\title{
Interstate Migration and Employer-to-Employer \\ Transitions in the U.S.: New Evidence from \\ Administrative Records Data
}

\author{
by \\ Henry Hyatt \\ U.S. Census Bureau
}

\author{
Erika McEntarfer \\ U.S. Census Bureau
}

Ken Ueda

University of MD

\section{Alexandria Zhang Johns Hopkins University}

\section{CES 16-44 October, 2016}

The research program of the Center for Economic Studies (CES) produces a wide range of economic analyses to improve the statistical programs of the U.S. Census Bureau. Many of these analyses take the form of CES research papers. The papers have not undergone the review accorded Census Bureau publications and no endorsement should be inferred. Any opinions and conclusions expressed herein are those of the author(s) and do not necessarily represent the views of the U.S. Census Bureau. All results have been reviewed to ensure that no confidential information is disclosed. Republication in whole or part must be cleared with the authors.

To obtain information about the series, see www.census.gov/ces or contact J. David Brown, Editor, Discussion Papers, U.S. Census Bureau, Center for Economic Studies 5K034A, 4600 Silver Hill Road, Washington, DC 20233, CES.Papers.List@census.gov. To subscribe to the series, please click here. 


\begin{abstract}
Recent evidence has suggested that interstate migration is in decline in the United States, which might imply that the labor market is becoming more rigid. However, the sharp post-2000 decline in the non-imputed interstate migration rate in the Current Population Survey (CPS), which has received considerable attention, is not reflected in other available data. In this paper, we use administrative records data to investigate labor mobility and migration within the U.S. We investigate the discrepancy in recent migration trends in the CPS and migration rates derived from administrative records sources using CPS microdata linked to administrative records on residential location. We find that a substantial fraction of CPS respondents who are cross-state migrants in the administrative records data do not report a cross-state move in the CPS, and that this disagreement has grown over time. Despite this disagreement in recent trends in overall interstate migration, rates and trends related to economic migration are remarkably similar in available data sources.
\end{abstract}

\footnotetext{
*We thank Rob Valletta, James Spletzer, and participants in the 2016 Allied Social Science Association conference and the U.S. Census Bureau research lunch for helpful comments and suggestions. Any opinions and conclusions expressed herein are those of the authors and do not necessarily represent the views of the U.S. Census Bureau. All results have been reviewed to ensure that no confidential data are disclosed. U.S. Census Bureau, Email henry.r.hyatt@census.gov U.S. Census Bureau, erika.mcentarfer@census.gov University of Maryland and U.S. Census Bureau, uedak@econ.umd.edu Johns Hopkins University and U.S. Census Bureau, azhang4@jhu.edu
} 


\section{Introduction}

In the early 1990s, approximately $3 \%$ of individuals in the Current Population Survey (CPS) reported moving to a different state within the U.S. in the last year. By the late2000s, that share had fallen by half. This sharp decline in residential mobility in the CPS has raised concerns in light of other recent evidence of declining flexibility in U.S. labor markets (Hyatt and Spletzer (2013); Molloy et al. (2016)). Internal migration within the U.S. plays an important role in reallocating labor across different labor markets and smoothing the labor market response to economic shocks. Tighter labor markets have been shown to attract a larger share of migrants (Dahl (2002); Wozniak (2010)) and migration plays a key role in reallocating workers to higher productivity areas, leading to greater economic growth (Hsieh and Moretti (2015)). If labor market flexibility declines, with fewer workers moving across employers and labor markets, this may mean that the U.S. will experience more prolonged recessions and slower productivity growth.

In this paper, we use administrative records data to explore the connection between interstate migration and job change, and how the rates of such moves have changed over time. First, we note that there is very little agreement on the timing or extent of any decline in interstate migration in the U.S. Second, there is very little agreement between changes in the overall migration rate and changes in the rate of job change: this is for

the simple reason that most interstate migration is not for economic reasons, and only a small fraction job changes involve a change in a workers state of employment. Third, when we focus on economic migration, that is, migration for job-related reasons, we find a much stronger relationship between trends for this subset of migrants and the overall pace of job change. While we are not the first to examine the connection between changes in labor reallocation and migration within the U.S., a unique contribution of our paper is the extensive use of administrative records data to address this question.

We begin by exploring the inconsistencies in recent trends in migration within the U.S. across data sources. The sharp decline in the CPS migration rate has motivated much of the literature on declining migration. However, when comparing migration rates in the CPS to other available data for the U.S., the CPS is a striking outlier, even when 
using the method suggested by Kaplan and Schulhofer-Wohl (2015). While the migration rate in the CPS falls by half between the early 1990s and the late 2000s, other available data suggest that the post-2000 rate of interstate migration is procyclical without a substantial trend over time. Throughout the 1980s and early 1990s, residential migration rates in the CPS and the state-to-state migration series published by the Internal Revenue Service (IRS) are largely in agreement (indicating an annual migration rate of about 3\%). However, starting around 2000, the trends begin to diverge, with sharp declines in the migration rate in the CPS and only modest changes in migration rates derived from administrative records data. By 2011, the CPS interstate migration rate was $1.5 \%$ and the corresponding IRS interstate migration rate was 2.4\%. Migration trends and levels in the American Community Survey (ACS) data largely mirror those in the administrative records data.

We utilize unique microdata from the Longitudinal Employer-Household Dynamics (LEHD) program that allow us to examine why the CPS migration rate diverges so sharply in recent years from migration rates derived from administrative records. Linking CPS microdata with administrative records on residential addresses (which share a common data source with the IRS migration series), we are able to compare self-reported migration in the CPS to changes in residential address in administrative records for the same individual. Using this linked data, we find there is a high rate of disagreement between survey responses of migrant status and changes in state of residence in the administrative records data for the same individual. Less than a third of CPS interstate migrants do not change state of residence in administrative records data, while close to half of CPS respondents whose state of residence changes in administrative records do not report a corresponding cross-state move in the CPS. Moreover, the share of CPS respondents that we observe changing state of residence in the administrative records data but not reporting a cross-state residential move in the CPS has increased since 2000. While timing differences between the two data sources (which can be caused by individuals who file taxes early or late) account for a substantial share of the mismatch, they do not account for the increasing frequency with which cross-state residential moves appear in 
the administrative records data but not the CPS.

Despite divergent trends in the residential migration rate in the CPS and administrative records data, we find that both data sources are remarkably consistent regarding the frequency with which workers change employers. In both the CPS and the LEHD data, approximately $7 \%$ of workers changed employers each quarter in the late 1990s and the employer-to-employer transition rate declines by about half by 2010. Moreover, when we focus attention specifically on rates of economic migration - defined as residential moves for economic reasons in the CPS, and residential moves that correspond with interstate employer-to-employer transitions in the administrative records data - we find these have also declined by about half during this period in both the CPS and LEHD data between 2000 and 2010. The decline in economic migration since 2000 accounts for three-fifths of the smaller decline in residential mobility in the administrative records data, while accounting for half of the decline in the CPS. Overall, our analysis suggests that any actual decline in migration rates in the U.S. may be smaller than indicated by the CPS, but that economic migration likely declined through the 2000s.

Previous studies have noted that changes in observable characteristics of the population contribute only a small part to the changes in internal migration. We confirm this result with administrative records data on workers and employers, which suggests these changes are driven by other fundamentals that impact migration. One of these fundamentals is the return to migration. If the economic benefits of moving across labor markets fall, migration rates would decline, all else equal. To investigate this, we examine the returns to migration, measured as the change in log earnings from the longdistance employer-to-employer transition, in the administrative records data since 2000. We find evidence that the returns to interstate migration declined in both the 2001 and 2007-2009 recessions, but recovered in the intervening expansions; we find no evidence of a declining trend in returns to migration in the 2000s. The cyclicality in migration returns is a probable cause of the cyclical pattern of cross-state migration we observe in the administrative records data during this time.

This paper is part of a larger literature studying the recent changes in migration 
and labor reallocation in the U.S. Molloy et al. (2011, 2014), Kaplan and SchulhoferWohl (2012, 2015), and Molloy et al. (2016) all examine the apparent decline in the CPS interstate migration rate in recent decades. These papers document that this decline is not driven by changes in the age distribution or homeownership. The most closely related paper to our investigation here is Molloy et al. (2014), who explore the connection between labor market dynamics and internal migration using the CPS and National Longitudinal Survey (NLS) data, and who argue that both phenomena exhibit long-run declines, and that these proposed long-run declines may be related. Like our paper, their findings are largely descriptive, but they argue that there have been declining benefits rather than increasing costs of migration across labor markets.

A separate literature has focused on the dramatic post-2000 decline in labor market dynamics (Lazear and Spletzer (2012); Hyatt and McEntarfer (2012); Hyatt and Spletzer (2013), 2016; Davis and Haltiwanger (2014); Molloy et al. (2016)). Such declines warrant attention as higher job and worker reallocation rates are generally associated with higher economic growth (Jovanovic and Moffitt (1990); Davis and Haltiwanger (2014)). From the perspective of individual workers, declining job mobility could dampen lifetime earnings growth, as earnings gains from job change are pronounced, especially for young workers moving up the job ladder ((Topel and Ward, 1992); Hyatt and McEntarfer (2012)). Hyatt and Spletzer (2013) show that only a small part of the decline in labor market dynamics is attributable to an aging workforce, and that lower rates of business formation in recent years explain a larger share of the decline. However, most of the decline in job mobility remains unexplained. Hyatt and Spletzer (2016) and Molloy et al. (2016) argue that better worker-firm matching have little explanatory power concerning changes in employment dynamics, in addition to compositional factors, with the noteworthy exception of the aging of the U.S. workforce.

This paper proceeds as follows. First, we describe our data sources. Next, we compare the trends in residential migration across these different data sources. Using CPS data linked with administrative records on residence, we then examine agreement between selfreported migration and residential migration in the administrative records data for the 
same set of respondents. We then explore employer-to-employer transitions and interstate economic migration. Next, we conduct shift-share decompositions of the changes in the residential and economic migration rates to assess the role of observable and unobservable factors in explaining these changes, again comparing results from CPS and LEHD data. Finally, we calculate earnings changes associated with economic moves to see if we find a similar trend in returns to migration in the administrative records data as has been found using survey data. A brief conclusion follows.

\section{Data}

A unique contribution of this paper is the use of administrative records data to examine the connection between changes in labor reallocation and interstate migration. As much of this literature uses more widely available survey data, we make extensive use of these data to put our results in context. Whenever practical, we restrict our sample to the civilian population aged 16 to 64 . With the survey data, we also exclude armed forces and individuals living in group quarters. As some of our key data are only available from 2000 forward, much of our analysis will focus on the more recent period, but we discuss pre-2000 trends for the subset of data for which they are available.

Current Population Survey (CPS)

The CPS is the most commonly used data source for the study of interstate migration. The Annual Social and Economic Supplement (ASEC, also called the "March CPS") asks respondents where they lived one year ago. ${ }^{1}$ The CPS also collects information on an individuals reason for migrating, one of which is starting or transferring to a new job, which has been analyzed by both Molloy et al. (2011) and Kaplan and Schulhofer-Wohl (2015) and so serves as our main measure of economic migration from the CPS. As recommended by Kaplan and Schulhofer-Wohl (2012), we exclude imputed migration responses, which change discontinuously in the early 2000s due to changes in procedures

\footnotetext{
${ }^{1}$ We download the CPS ASEC data from the University of Minnesotas Integrated Public Use Microdata Series; see Ruggles et al. (2010).
} 
for handling non-response. ${ }^{2}$

Employer-to-employer transitions can be measured in the CPS in both the ASEC and the monthly CPS. The CPS ASEC began asking a retrospective question on the number of jobs a respondent held in the last year starting in 1976. If the respondent reported working for more than one employer in the last year, this suggests that the worker experienced a employer-to-employer transition. The time trend of this proxy has been analyzed by Farber (1999), Stewart (2007), Hyatt (2015), and Molloy et al. (2016). In addition to this proxy measure, it is possible to measure the employer-to-employer transition rate directly from the monthly CPS data, following Fallick and Fleischman (2004). ${ }^{3}$ We use both measures as a comparison to the employer-to-employer transition rate series we construct from the LEHD data. It is important to note that the CPS does not track movers, and so does not permit comparisons of earnings before and after an employer-to-employer transition.

\section{American Community Survey (ACS)}

Because the post-2000 migration trends in the CPS diverge substantially from the IRS migration series, we use the American Community Survey (ACS) as an additional source of data to benchmark migration trends in recent years. The ACS is a large nationally representative cross-sectional survey of the United States. ${ }^{4}$ To identify migrants, the ACS asks a retrospective question that is similar to the one asked in the CPS. There are some notable differences between the two surveys, however. First, the ACS pursues nonrespondents more intensively than the CPS (Koerber (2007)). As people who move more frequently may be less likely to respond to surveys, migration rates in the ACS may be higher than the CPS. Second, the ACS asks respondents about their current address, not their usual address (the concept used in the CPS). This largely impacts college students who, in the ACS, are primarily in the group quarters sample, which we exclude. In

\footnotetext{
${ }^{2}$ As noted by Kaplan and Schulhofer-Wohl (2012), it is also necessary to exclude individuals with migration responses assigned from the householder (i.e., primary respondent) if the householders response is imputed.

${ }^{3}$ We download the CPS monthly data from NBER at http://www.nber.org/data/cps_basic.html (last accessed: May 18, 2016).

${ }^{4}$ We download ACS data for the year 2001 onward from the iPUMS website at https://usa.ipums.org/usa/ (last accessed: May 18, 2016), see Ruggles et al. (2010).
} 
the CPS, households that include college students residing elsewhere are instructed to include them in the household. ACS microdata is available from 2001 to the present, and provides migration information as well as demographic characteristics, although it neither asks migrants their reason for moving nor collects information on employer-toemployer transitions, so we are unable to measure the rate of economic migration using the ACS. ${ }^{5}$ We also use data for the year 2000 from the Census 2000 Supplemental Survey, the precursor to the ACS, which serves as our initial year of ACS migration data. ${ }^{6}$

\section{Internal Revenue Service (IRS)}

Following other recent studies, we also use data provided by the IRSs Statistics of Income program to calculate gross interstate migration rates. ${ }^{7}$ As mentioned above, we are able to produce a longer time series with these data that is comparable to the length of the CPS series. The published IRS migration rates are calculated from year-to-year changes in state of residence based on individual tax returns. In the published IRS migration statistics, the number of personal exemptions on each tax return is used to approximate the number of individuals (as distinct from households).

\section{Longitudinal Employer-Household Dynamics (LEHD)}

We use linked employer-employee data from the LEHD program at the U.S. Census Bureau that contain longitudinal information on residential location and employment. The LEHD data link multiple administrative records and survey data sources to create a framework that encompasses both household and business characteristics at the "job" level, defined as a distinct employer-employee combination. The data we use to construct

\footnotetext{
${ }^{5}$ Kaplan and Schulhofer-Wohl (2015) exclude pre-2005 ACS data from their study due to concerns about changes in survey methodology that occurred between 2001 and 2005, the year in which it reached its final size as a 1-in-60 sample of the U.S. population. However, we include estimates for pre-2005 years here as the ACS migration rate does not appear to us to change for reasons that we could link to changes in survey methodology.

${ }^{6}$ Migration in the ACS for 2000 is calculated using data from http://www2.census.gov/programssurveys/acs/data/pums/2000/.

${ }^{7}$ Recent years (1990-2014) of IRS data are available from the IRS website at https://www.irs.gov/uac/soi-tax-stats-migration-data (last accessed: May 18, 2016). Data for earlier years were downloaded from the website of the National Archives, and although there is not a main page with links to these files, they can be downloaded by following the URL that contains a query for these data; see https://catalog.archives.gov/search?q=*:*\&rows=20\&tabType=all\&facet=true\&facet.fields=oldScope, level,materialsType,fileFormat,locationIds, dateRangeFacet\&highlight=true\&f.parentNaId=646447\&f.level= fileUnit\&sort=naIdSort\%20asc (last accessed: May 18, 2016).
} 
employment histories consist of quarterly worker-level earnings submitted by employers for the administration of state unemployment insurance benefit programs, linked to establishment-level data collected for the Quarterly Census of Employment and Wages program. As of this writing, all 50 states and the District of Columbia have shared these data as part of the Local Employment Dynamics federal-state partnership. LEHD data coverage is quite broad, covering about $95 \%$ of private sector employment, as well as state and local government. ${ }^{8}$

Information on the residence of workers in the LEHD system of records is sourced from a file internally called the Composite Person Record (CPR). The CPR is constructed from multiple administrative records data sources, including some federal program data, but the most common source of residential address is federal tax filing (Leggieri et al. (2002)). Thus our residence microdata are very similar to that used by the IRS to produce the IRS migration statistics. We use the following assignment rule to time migrations in the administrative records data: if the residential address in the administrative records data changes between years, we assume a residential move occurred between April of the previous year and April of the current year. Obviously the ability to file taxes earlier or later may mean we mistime a subset of migrations but, overall, we do not expect timing issues to materially impact the results. Production of the CPR was discontinued after 2010, and so our primary analysis of the LEHD trend in interstate migration ends there. ${ }^{9}$

The LEHD data allow us to identify job movers who also had a residence change at the time of the job change. One objective of this paper is to evaluate the role of employer-to-employer transitions in explaining changes in the interstate migration rate. To identify these employer-to-employer transitions in the LEHD data, we link the main jobs in each quarter of a workers employment history. ${ }^{10}$ When a worker separates from

\footnotetext{
${ }^{8}$ For an overview of the LEHD data, see Abowd et al. (2009).

${ }^{9} \mathrm{~A}$ replacement residential file for the LEHD has been constructed from administrative records for later years, called the LEHD Residence Candidacy File (RCF). Migration rates appear higher in the RCF than the CPR. The IRS published migration rates also increases discontinuously starting with the 20112012 migration rate, which (1) moved from a January 1 to late September to January 1 to December 31 reference window, and (2) entailed matching returns for primary, secondary, and dependent filers, instead of only the primary filer; see Internal Revenue Service (2012). Note that the 2012-2013 RCF migration rate is $2.7 \%$, which is similar to the IRS migration rate, which also rounds to $2.7 \%$.

${ }^{10}$ Linking all main jobs (defined as the employer at which a given worker had maximal earnings in a given quarter) in a workers employment history is also used to identify employer-to-employer transitions
} 
a job and begins work at a new job in either the same quarter or the next, we classify this job move as an employer-to-employer transition. ${ }^{11}$ Transitions with longer periods of non-employment (at least one full-quarter of zero earnings) are not considered employerto-employer transitions, but movements into and out of employment.

In this paper, we define interstate migration in the LEHD data as "economic" if the individual changes both employers and residence in the administrative records data, and both the new employer and the new residence are in a different state. ${ }^{12}$ This approach has a few limitations. A worker who has been long unemployed in one location who moves to a better labor market to find work will not be classified as making an economic move under our definition (this is, however, one of the least cited reasons for making a residential move in the CPS). Similarly, a trailing spouse who does not work (either voluntarily or involuntarily) in either the origin or destination market would also not be classified as making an economic move, even if the move was motivated by a new job for the household head. We will also classify some moves as being economic that are driven by noneconomic factors (such as when individual takes a new job to be closer to family).

The availability of LEHD job-level data varies by state, due to states joining the Census-state partnership at different times, see Henderson and Hyatt (2012). Therefore, when we use these data to measure economic migration, we restrict our analysis to the set of states with jobs data beginning in 1999. ${ }^{13}$

in Hyatt and McEntarfer (2012) and Haltiwanger et al. (2015).

${ }^{11}$ Specifically, the transition is between employers measured at the level of the state Unemployment Insurance account. These accounts can and often do contain multiple establishments, so within-state transfers between establishments are not counted as employer-to-employer transitions. In contrast, transfers within a firm but across states are counted as employer-to-employer transitions, as the accounts are state-specific.

${ }^{12}$ Specifically, we classify a move as economic if (1) the worker changes employers between the second quarter of the previous year and the first quarter of the current year and the new employer is located in a different state, and (2) the worker changes state of residence in the administrative records data in that year.

${ }^{13}$ These 34 states are California, Colorado, Connecticut, Delaware, Florida, Georgia, Hawaii, Idaho, Illinois, Indiana, Iowa, Kansas, Louisiana, Maine, Maryland, Minnesota, Missouri, Montana, Nevada, New Jersey, New Mexico, North Carolina, North Dakota, Oregon, Pennsylvania, Rhode Island, South Carolina, South Dakota, Tennessee, Texas, Virginia, Washington, West Virginia, and Wisconsin. These states accounted for about $74 \%$ of the U.S. population in 2010. 


\section{Interstate Migration in the U.S., 1981-2014}

Comparison of Interstate Migration Rates

We begin by comparing the time trend of residential migration rates the CPS, ACS, IRS, and LEHD data from the mid 1980s to 2014, as shown in Figure 1. The CPS and IRS data have the longest time series, and both show a decline in interstate migration from approximately $3 \%$ in 1985 to $2.5 \%$ in 2000 . Starting in 2000, however, trends in the CPS and IRS series diverge substantially. Interstate migration in the CPS falls sharply, and is $1.4 \%$ by 2010 . The IRS migration rate is more procyclical, rising to $2.7 \%$ in 2006 before falling to $2.2 \%$ by 2010 . The ACS migration rate closely mirrors the levels and trends in the IRS published data. As expected given similar source data, the LEHD interstate migration rate calculated from the CPR closely mirrors the IRS published data for all available years. ${ }^{14}$

The sharp decline in the CPS migration rate has motivated much of the literature on declining migration. However, as shown in Figure 1, when comparing migration rates across multiple data sources, migration rates fall much more sharply in the CPS than in any other data source. While this divergence is apparent in other papers in this literature, we believe we are the first to explore its cause. In the next section, we take advantage of our unique access to CPS microdata linked to administrative records to investigate possible causes of the larger decline in interstate migration in the CPS relative to the LEHD data, the latter of which exhibit similar levels and trends to the IRS and ACS data.

Evidence from Matched CPS and LEHD Data

In this section, we use CPS respondent records that have been probabilistically matched to administrative records data to compare migration calculated from self-response to migration calculated from administrative records on residence location, which allows

\footnotetext{
${ }^{14}$ In Appendix A, we show the correlations between the series shown in Figure 1 in Table A1. Despite the divergent trends between the CPS, ACS, and IRS data, the intertemporal correlation between the series are still quite high (between 0.6 and 0.8), reflecting similar cyclicality in the three series. This is in part because the CPS has a level shift downward from 2004-2006, which makes the series appear divergent without subtracting as much from their intertemporal movements, which are otherwise quite close.
} 
us to distinguish between explanations for this divergence. If the more dramatic decline in migration in the CPS is driven by changes in survey response error, we should see some evidence of this in the matched data. Conversely, the increasing divergence in migration rates in the LEHD and CPS data could be driven by changes in the frame of the administrative records data. For example, the population of tax filers could be changing over time in such a way that more migrants are entering the data, dampening the decline in the migration rate.

Figure 2 compares interstate migration rates for CPS respondents as measured by survey response or by administrative record data, focused on the period 2002-2009, where the divergence between the CPS and the other data sources is most pronounced. As seen in Figure 2, the divergence between self-reported migration and the administrative records data is apparent even within the linked subset, with self-reported migration rates falling 0.6 percentage points (for all CPS households, as well as the linked households) and the migration rate calculated from the administrative records remaining more or less constant, falling by 0.1 percentage points overall and by 0.3 percentage points in the linked data. This suggests that changes in the frame of tax filers or in unit non-response bias in the CPS explain less than half of the divergence in the migration rates between the CPS and administrative records sources.

In Figure 3, we examine this discrepancy further, creating three separate migration rates for CPS respondents who: (1) report an interstate migration to the CPS but have no corresponding change in state of residence in the administrative records data, (2) change state of residence in the administrative records data, but do not report a cross-state move to the CPS, and (3) are migrants in both data sources. This exercise reveals the substantial disagreement in the rate of interstate migration between the different data sources. In 2002, the percent of CPS respondents who report a cross-state migration in the CPS but do not change state of residence in the administrative records data was $0.6 \%$. Given that the CPS migration rate is just under $2.2 \%$ in 2002, this means that $27.7 \%$ of CPS respondents who report a move in the CPS do not change their state of residence in the administrative records data. The percent of CPS respondents who change states 
in the administrative records data but not in the CPS is almost twice as large, about $1.0 \%$ in 2002. Overall, under a third (29.5\%) of CPS migration responses are not present in the administrative records data, while just under half (48.5\%) of migrations present in the administrative records data are not reported by CPS respondents. The trends in particular shed light on why the CPS interstate migration rate disagrees with the rate derived from administrative records sources: the share of respondents who report migrating in the CPS but do not appear to migrate in the administrative records has fallen over time, while the share of migration that appears in the administrative records but not in the CPS has increased, especially around 2005.

Finally, we explore the extent to which timing issues impact the mismatch, with results presented in Table 1. The first two columns of Table 1 show the percentage of the matched data for which the observed CPS move (between a given pair of origin and destination states) appears in the administrative records data in either the preceding or subsequent year. That migration in the administrative records more often appears after the CPS than before suggests that late tax filers have a larger impact on the disagreement between the CPS and administrative records data. The third column captures the percentage of the sample that move to an adjacent state in the CPS where the origin state is the same in both the CPS and the administrative records, as there may be differences in the way in which these data sources handle short-term or temporary moves. ${ }^{15}$ The fourth column presents the residual. Between 2005 and 2007, when the CPS-only category exhibits its most dramatic decline, we only see modest declines in the share of border-state moves and in the residual.

\footnotetext{
${ }^{15}$ We also investigate whether one-time changes in the administrative records data explain many of the cases where the migration appears only in the administrative data. This pattern is more common in the administrative data, either because more immediately reversed migrations appear in the administrative data or because different sources of administrative data sometimes disagree on state of residence. As shown in Appendix Table A2, we find that this issue only accounts for about $15 \%$ of LEHD-only migrations and does not exhibit a strong trend over time.
} 


\section{Interstate Migration and Employer-to-Employer Tran- sitions}

\section{Trends in Employer-to-Employer Transitions}

We now examine the role of employer-to-employer transitions in interstate migration. Given the large divergence in interstate migration trends between the CPS and LEHD data during this decade, we check to see if they compare to changes in labor reallocation, measured by the employer-to-employer transition rate. While the annual proxy for employer-to-employer transitions in the CPS can be compared to interstate migration directly in the microdata, the monthly employer-to-employer transitions cannot as they are only recorded when a household does not move. Figure 4 shows quarterly employerto-employer transition rates calculated from the monthly CPS and LEHD, as well as the annual proxy from the CPS, defined as the fraction of those employed who worked for multiple employers in the last year. ${ }^{16}$ Perhaps surprisingly given the divergence in residential migration rates in these two data sources, here all three measures track each other very closely between 2000 and 2010. Differences widen after 2010 with the LEHD data showing more of a recovery than the CPS. ${ }^{17}$ In all three series, the employer-to-employer transition rate is procyclical, and the implied quarterly employer-to-employer transition rate is very similar in levels to the LEHD series. The LEHD employer-to-employer transition rate reached a high of $7.5 \%$ in 2000 , declined to $5.8 \%$ in 2003 , recovered to $6.6 \%$ by 2005 , reached a low of $4.4 \%$ during the 2007-2009 recession, and rebounded to $5.8 \%$ by the end of 2013. This evidence on employer-to-employer transition rates is consistent with the findings of Hyatt and McEntarfer (2012) and Hyatt (2015).

The much longer annual proxy for the employer-to-employer transition rate suggests that while employer-to-employer transitions were also cyclical between 1980 and 1998, they did not exhibit a downward trend. ${ }^{18}$ Therefore, declines in employer-to-employer

\footnotetext{
${ }^{16}$ We also show CPS rates for the set of restricted states in Figure A3.

${ }^{17}$ The post-2006 CPS monthly series also have a greater prevalence of missing employer-to-employer transition responses, which makes comparison of more recent years to earlier ones difficult.

${ }^{18}$ This annual proxy for the employer-to-employer transition rates shows no obvious trend during the 1980s and 1990s. Generally, data sources on reallocation do not show a consistent trend over this period, and, depending on the series, employment reallocation rates may have increased, stayed roughly constant, or declined. Decker et al. (2013) and Molloy et al. (2016) suggest that labor reallocation
} 
moves overall do not appear to drive the observed changes in residential migration in the CPS or IRS data from the 1980 s to $2000 .{ }^{19}$ Moreover, this similarity between the CPS and the LEHD data with respect to employer-to-employer transition rates suggests that the discrepancy in residential migration rates is not a result of a systemic error in the CPS, such as a weighting issue that would affect other outcomes, which motivates a separate investigation into where and why the CPS and LEHD data differ in identifying residential moves. ${ }^{20}$

\section{Economic Migration}

To examine the impact of declines in job mobility on interstate migration more closely, we first assess the extent to which residential migration is economic in nature, and measure the proportion of individuals changing residence across states who concurrently changed their state of employment in the LEHD and those who reported moving because of a job transfer or starting a new job in the CPS. So-defined economic migration rates are shown in Figure 5. Economic migration accounts for more than a third (35.4\%) of total residential migration in the CPS, while it is closer to one quarter $(27.7 \%)$ in the LEHD. The cyclicality of the economic migration rate, like in the residential migration rate, is again more pronounced in the LEHD data than in the CPS. However, interstate economic migration rates in the CPS and LEHD data are much more similar than overall residential migration, with respect to both levels and trends. ${ }^{21}$

To further explore changes in the migration rate, we focus on the years 2000 and 2010, over which interstate migration declined. Given the stronger decline in interstate

may have declined from the 1970s to the 1990s. Moscarini and Thomsson (2007) and Kambourov and Manovskii (2008) provide evidence that mobility across industries and occupations increased over the span of those decades, while Hyatt (2015) and Hyatt and Spletzer (2016) provide evidence that labor reallocation had little trend over this same period. Despite these different historical trends, data sources agree that in the 15 years since 2000, employment reallocation declined precipitously.

${ }^{19}$ The CPS ASEC asks about both migration and the number of employers worked in the last year, so one might alternatively measure economic migration as the rate with which individuals both changed states and worked at multiple employers in the last year. Although the rates are similar for this alternative measure, there is also substantial disagreement; see Appendix Figure A.1.

${ }^{20}$ Correlations between different employer-to-employer transition rates and migration rates are shown in Appendix Table A1. The frequency with which workers report multiple employers in the past year is very strongly correlated with the interstate migration rate, with a correlation of 0.867 for the longer 1981-2014 series and even higher at 0.916 for the more recent years.

${ }^{21}$ For CPS data with the same state-based sample selection criteria, see Appendix Figure A.3, which looks virtually the same as Figure 5, with the CPS migration rates being only slightly lower. 
migration in the CPS, we are surprised to find that levels and trends for interstate moves for job-related reasons are more similar in the CPS and LEHD data. In Table 2 we see that overall interstate migration rates fell by $50.2 \%$ between 2000 and 2010 in the CPS, compared to $20.1 \%$ in the LEHD data. ${ }^{22}$ There are also large differences in the proportionate decline in migrations for job-related reasons, which are $67.0 \%$ and $45.5 \%$ in the CPS and LEHD, respectively. However, economic migration rates in both series are so small that these percentage differences in the change exaggerate the absolute differences between the two series. Economic migration in the CPS fell from $0.9 \%$ in 2000 to $0.5 \%$ in 2010, and in the LEHD data, the rate fell from $0.8 \%$ in 2000 to $0.5 \%$ in 2010 .

Given the differences in the overall change in interstate migration between the CPS and LEHD, we find a stronger role for job mobility in explaining changes in interstate migration in the LEHD data. Three-fifths of the change in the interstate migration rate between 2000 and 2010 in the LEHD data is accounted for by the decline in economic migration, compared to half of the change in interstate migration rates for the corresponding period in the CPS data. Nevertheless, both numbers highlight the importance of investigating how returns to economic migration in particular have changed over time.

CPS respondents are able to give other reasons for migrating, which we also report in Table 2. The change in family-related moves accounts for the largest share of the decline in non-economic migration between 2000 and 2010. The new job/job transfer reason is by far the largest component of economic migration in the CPS, as well as one-third of all interstate migrations in 2000, with lost job/job search having the lowest frequency of all reasons for migration, or less than 5\% of migrations in 2000. Additionally, new job/job transfer experienced the largest proportionate decline over the period, with other job-related a close second but at a much lower level of occurrence, while lost job/job search actually increased slightly. This stands as further evidence that employer-toemployer transitions are the primary mechanism driving interstate migrations that have an economic motive.

\footnotetext{
${ }^{22}$ These percentages are proportionate changes, defined as the difference between the rate in 2010 and in 2000 divided by the average of the rate in 2000 and in 2010 .
} 


\section{Changes in Interstate Migration and Economic Mi- gration: 2000-2010}

\section{The Role of Composition in Changing Interstate Migration}

Because we have rich microdata on migration from the CPS and LEHD, we can explore additional mechanisms that may have affected interstate migration and its economic component. The LEHD data especially provide unique information, such as whether the decline in startups explains changes in interstate migration or its economic component. We perform a shift-share analysis following Hyatt and Spletzer (2013) and Decker et al. (2013). Formally, this decomposition can be expressed as:

$$
\Delta Y_{t}=\sum_{i} \Delta S_{i t} \bar{Y}_{i}+\sum_{i} \Delta Y_{i t} \bar{S}_{i}
$$

where $\Delta Y_{t}$ is the change in the migration rate from 2000 to 2010, $i$ represents each group within a demographic category (e.g. age), $Y_{i}$ is the average transition rate for each $i, S_{i}$ is the average share of each $i, \Delta Y_{i t}$ is the change in the transition rate for each $i$, and $\Delta S_{i t}$ is the change in the share of individuals within each $i$. The first component of the right-hand side captures the fraction of the change attributable to compositional changes, or explained variation, while the second component captures the fraction attributable to within-group changes, or unexplained variation.

With both the CPS and LEHD data, we decompose residential and economic migration by age, gender, race and ethnicity, education, as well as by employment characteristics, the results of which are shown in Table 3. Compositional changes in age contribute the most among demographic characteristics to the change in residential migration in both data sources: $7 \%$ in the CPS and $16 \%$ in the LEHD, which is consistent with the fact that the U.S. population has been aging and older workers are less likely to move than younger workers. Similar results hold for the economic migration rate $-9.0 \%$ for the CPS and $12.0 \%$ for the LEHD. Other demographic characteristics have little explanatory power. This is consistent with the findings of Hyatt and Spletzer (2013) and Molloy et al. (2016) that the aging U.S. population helps explain declines in employment reallocation 
and population migration rates.

We see large differences in the explanatory power of economic characteristics between the CPS and the LEHD. Although Table 3 shows the majority of these economic categories matter little for residential migration, different patterns arise when decomposing the economic migration rate. For economic migration in the CPS, the employment composition effect is roughly $2 \%$, contrasted with $11 \%$ in the LEHD. This large difference likely arises from the way we define an economic migration in the LEHD: we use employment change during a residential move to define economic migration, which is more likely to include someone who was previously employed. We observe negligible effects of firm characteristics within both the LEHD and CPS, which are calculated only for the subset of workers with positive earnings. ${ }^{23}$ This suggests less of a role for declining entrepreneurship (i.e., changes in the firm age distribution) in changing migration than Hyatt and Spletzer (2013) and Decker et al. (2013) documented explain a small but noticeable share of job and worker reallocation rates. Overall, these decompositions provide further evidence that most of the change in interstate migration rates should be attributed to changes in migration behavior within demographic and employment groups.

\section{Changes in the Return to Interstate Migration}

We now address whether the cyclical patterns of economic migration might be associated with differential returns to migration. Measuring earnings changes associated with economic migrations is a feasible endeavor as the LEHD has a record of each workers longitudinal earnings history. We calculate the log earnings changes associated with an interstate job move as compared to earnings changes associated with all other job changes. For the subset of workers who have a state-to-state, employer-to-employer transitions for a pair of years that indicate residential migration, we can date the migration to the quarter of job change.

\footnotetext{
${ }^{23}$ It is possible to code the non-employed, who by definition do not have a firm size, age, or industry. When we did such tabulations (not reported), we found effects similar in magnitude to that of employment. These changes were driven by changes in the non-employed category rather than changes in the firm size, firm age, or industry groups, hence we only report decomposition results for workers with positive earnings for categories that report the results of a firm characteristic. All other decompositions are done on the full population age 16-64.
} 
Figure 6 shows the trend in annual log earnings changes associated with two types of labor market transitions: an interstate employer-to-employer transition with a change in state of residence, and employer-to-employer transitions that do not involve a change in the workers state of residence. As a baseline, those who are continuously employed for two years at the same employer but not change employers, which we call job stayers, are also shown. The difference in log earnings is a measure of the percentage change in earnings, and so is straightforward to interpret. Job stayers have far lower earnings increases, which dip down to below zero during the height of the Great Recession. Consistent with the evidence in Hyatt and McEntarfer (2012), workers who undergo employer-to-employer transitions see substantial increases in earnings, and these earnings increases are highly procyclical. In the year 2000, in the year 2005, and in the year 2010, earnings increase by about $15 \%$ for workers who changed jobs but did not change their state of residence. This change fell to $9 \%$ during the 2001 recession and 4\% during the 2007-2009 recession.

Individuals who change both states of work and residence have lower earnings changes, which are also procyclical and in the range of $3 \%$ to $14 \%$. It initially seems counterintuitive that interstate migrants have lower earnings increases than non-migrants since there is a positive cost to moving. However, migrants have substantially higher (by $30 \%-40 \%$ ) earnings than non-migrants while at the same time experience approximately the same earnings change in absolute terms as non-migrants. Overall, there is no obvious trend in Figure 6 that would indicate returns to economic migration have declined over the period. $^{24}$

\section{Conclusion}

Recent studies including Hyatt and Spletzer (2013), Davis and Haltiwanger (2014), and Molloy et al. (2016) have speculated that there may be a relationship between recent trends in interstate migration and employment reallocation. We have shown that this

\footnotetext{
${ }^{24}$ It is possible that these changes in earnings are driven by selection. Therefore, we conducted two propensity score analyses that hold constant the probability of migrating. If the earnings changes associated with migrating are higher for those whose observable characteristics indicate that they are more likely to migrate, then the predicted returns to migration may be constant. In Appendix B, we see that Figure 6 is robust to an elementary selection correction technique that uses propensity score matching.
} 
relationship is not a simple one, for the reason that most interstate migrations do not occur for job-related reasons, and interstate migration accounts for a small share of economic migration. In contrast, post-2000 trends in employment reallocation show fairly consistent declines. The overall trend in interstate migration is puzzling, and it remains an open question whether there is a long-run decline in interstate migration, or whether the rate of interstate migration is any different now than it was in the year 2000 .

To make some progress on understanding the trend in interstate migration, we investigated the discrepancy in recent migration trends in CPS and IRS data using confidential CPS microdata linked to administrative records data on residential location. We found that a substantial fraction of CPS respondents who are cross-state migrants in the administrative records data do not report a cross-state move in the CPS, and that this disagreement has grown over time. Our analysis rules out that changes in the population of tax filers is responsible for the divergence in the migration rates, as it is strongly evident even in the subset of CPS respondents who were matched to administrative records data. Timing issues account for a substantial share of the disagreement, but not the growing share of CPS respondents who appear to change state of residence in the administrative records data but do not report a cross-state move to the CPS, which accounts for much of the divergence between CPS and IRS migration rates. We conclude from this analysis that any actual decline in interstate migration may be milder than suggested in CPS data.

Despite this disagreement in recent trends in interstate migration overall, economic migration rates and trends are remarkably similar in both the CPS and administrative records data. In fact, both data sources suggest sharp declines in economic migration, consistent with declining rates of job change found in previous research. Furthermore, we find evidence that changes in the rate of economic migration in the U.S. explain about half of the change in migration in both the CPS and administrative records data. When we investigate whether changes in rates of economic migration are associated with declining returns to migration, we find that the return to migration is procyclical but shows no evidence of a declining trend. 


\section{References}

Abowd, John M, Bryce E Stephens, Lars Vilhuber, Fredrik Andersson, Kevin L McKinney, Marc Roemer, and Simon Woodcock, "The LEHD Infrastructure Files and the Creation of the Quarterly Workforce Indicators," Producer Dynamics: New Evidence from Micro Data, 2009, 68, 149.

Dahl, Gordon B, "Mobility and the return to education: Testing a Roy model with multiple markets," Econometrica, 2002, 70 (6), 2367-2420.

Davis, Steven J and John Haltiwanger, "Labor market fluidity and economic performance," Technical Report, National Bureau of Economic Research 2014.

Decker, Ryan, John Haltiwanger, Ron Jarmin, and Javier Miranda, "The Secular Decline in Business Dynamism in the US," Manuscript, University of Maryland, 2013.

Fallick, Bruce and Charles A Fleischman, "Employer-to-employer flows in the US labor market: The complete picture of gross worker flows," 2004.

Farber, Henry S, "Mobility and stability: The dynamics of job change in labor markets," Handbook of labor economics, 1999, 3, 2439-2483.

Haltiwanger, John, Henry Hyatt, and Erika McEntarfer, "Cyclical reallocation of workers across employers by firm size and firm wage," Technical Report, National Bureau of Economic Research 2015.

Henderson, Cody and Henry R Hyatt, "Estimation of Job-to-Job Flow Rates Under Partially Missing Geography," US Census Bureau Center for Economic Studies Paper No. CES-WP-12-29, 2012.

Hsieh, Chang-Tai and Enrico Moretti, "Why do cities matter? Local growth and aggregate growth," Technical Report, National Bureau of Economic Research 2015.

Hyatt, Henry R, "The decline in job-to-job flows," IZA World of Labor, 2015. 
_ and Erika McEntarfer, "Job-to-job Flows and the Business Cycle," US Census Bureau Center for Economic Studies Paper No. CES-WP-12-04, 2012.

_ and James R Spletzer, "The recent decline in employment dynamics," IZA Journal of Labor Economics, 2013, 2 (1), 1-21.

_ and _ , "The shifting job tenure distribution," Labour Economics, 2016.

Jovanovic, Boyan and Robert Moffitt, "An Estimate of a Sectoral Model of Labor Mobility," Journal of Political Economy, 1990, 98 (4), 827-852.

Kambourov, Gueorgui and Iourii Manovskii, "Rising occupational and industry mobility in the United States: 1968-97," International Economic Review, 2008, 49 (1), $41-79$.

Kaplan, Greg and Sam Schulhofer-Wohl, "Interstate migration has fallen less than you think: Consequences of hot deck imputation in the Current Population Survey," Demography, 2012, 49 (3), 1061-1074.

_ and _ , "Understanding the long-run decline in interstate migration," Technical Report, National Bureau of Economic Research 2015.

Koerber, Kin, "Comparison of ACS and ASEC Data on Geographic Mobility: 2004," Manuscript, US Census Bureau. Available at http://www. census. gov/acs/www/library/by_year, 2007.

Lazear, Edward P and James R Spletzer, "Hiring, churn, and the business cycle," The American Economic Review, 2012, 102 (3), 575-579.

Leggieri, Charlene, Arona Pistiner, James Farber et al., "Methods for Conducting an Administrative Records Experiment in Census 2000," in "Proceedings of the Survey Research Methods Section, American Statistical Association” 2002.

Molloy, Raven, Christopher L Smith, and Abigail K Wozniak, "Declining migration within the US: the role of the labor market," Technical Report, National Bureau of Economic Research 2014. 
_, _, and Abigail Wozniak, "Internal migration in the United States," The Journal of Economic Perspectives, 2011, 25 (3), 173-196.

Molloy, Raven S, Christopher L Smith, Riccardo Trezzi, and Abigail Wozniak, "Understanding Declining Fluidity in the US Labor Market," Technical Report, Board of Governors of the Federal Reserve System (US) 2016.

Moscarini, Giuseppe and Kaj Thomsson, "Occupational and Job Mobility in the US," The Scandinavian Journal of Economics, 2007, 109 (4), 807-836.

Ruggles, Steven, Matthew Sobek, Trent Alexander, Catherine A Fitch, Ronald Goeken, Patricia Kelly Hall, Miriam King, and Chad Ronnander, "Integrated Public Use Microdata Series: Version 3.0 [Machinereadable database]. Minneapolis: Minnesota Population Center [producer and distributor], 2004," 2010.

Stewart, Jay, "Using March CPS data to analyze labor market transitions," Journal of Economic and Social Measurement, 2007, 32 (2, 3), 177-197.

Topel, Robert $\mathbf{H}$ and Michael $\mathbf{P}$ Ward, "Job Mobility and the Careers of Young Men," The Quarterly Journal of Economics, 1992, pp. 439-479.

Wozniak, Abigail, "Are college graduates more responsive to distant labor market opportunities?," Journal of Human Resources, 2010, 45 (4), 944-970. 
Figure 1: Interstate Residential Migration Rates

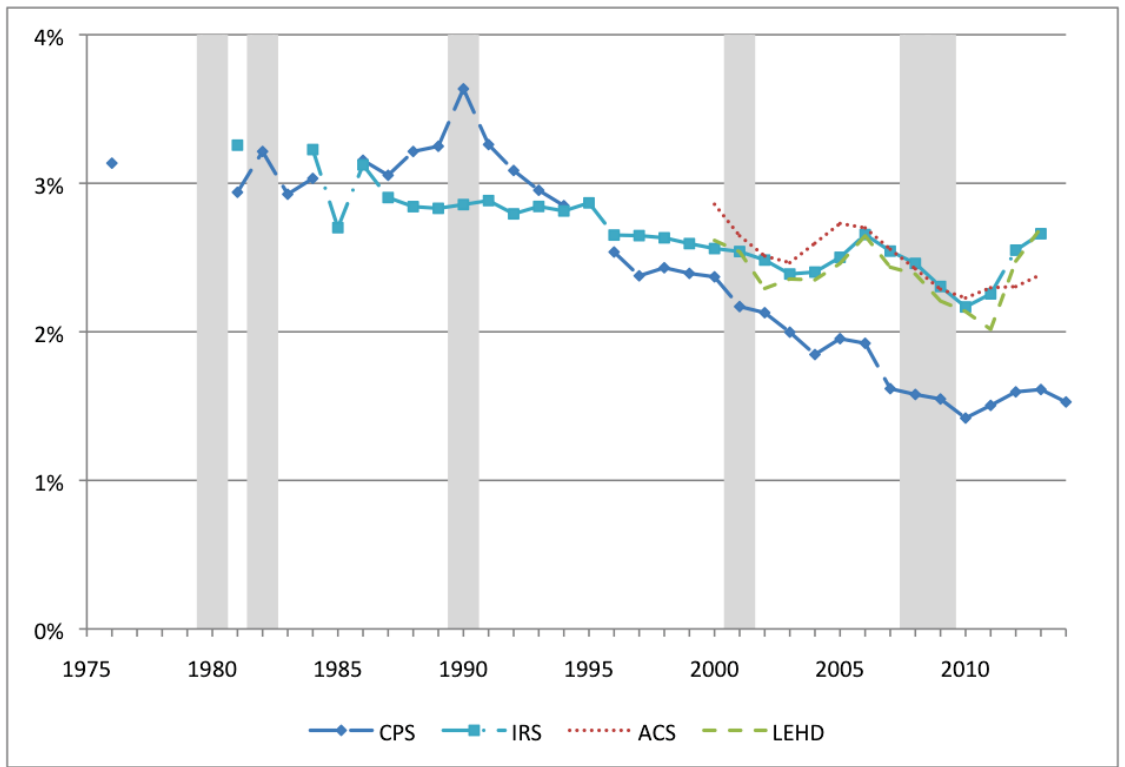

Notes: Shaded areas denote recessions as determined by the National Bureau of Economic Research. Authors tabulations of Current Population Survey (CPS), American Community Survey (ACS), and the Longitudinal Employer-Household Dynamics (LEHD) microdata, as well as published tabulations of Internal Revenue Service (IRS) data. CPS, ACS, and LEHD migration rates are calculated for the population age 16-64.

Figure 2: CPS and LEHD Migration Rates vs. Matched CPS-LEHD Subset

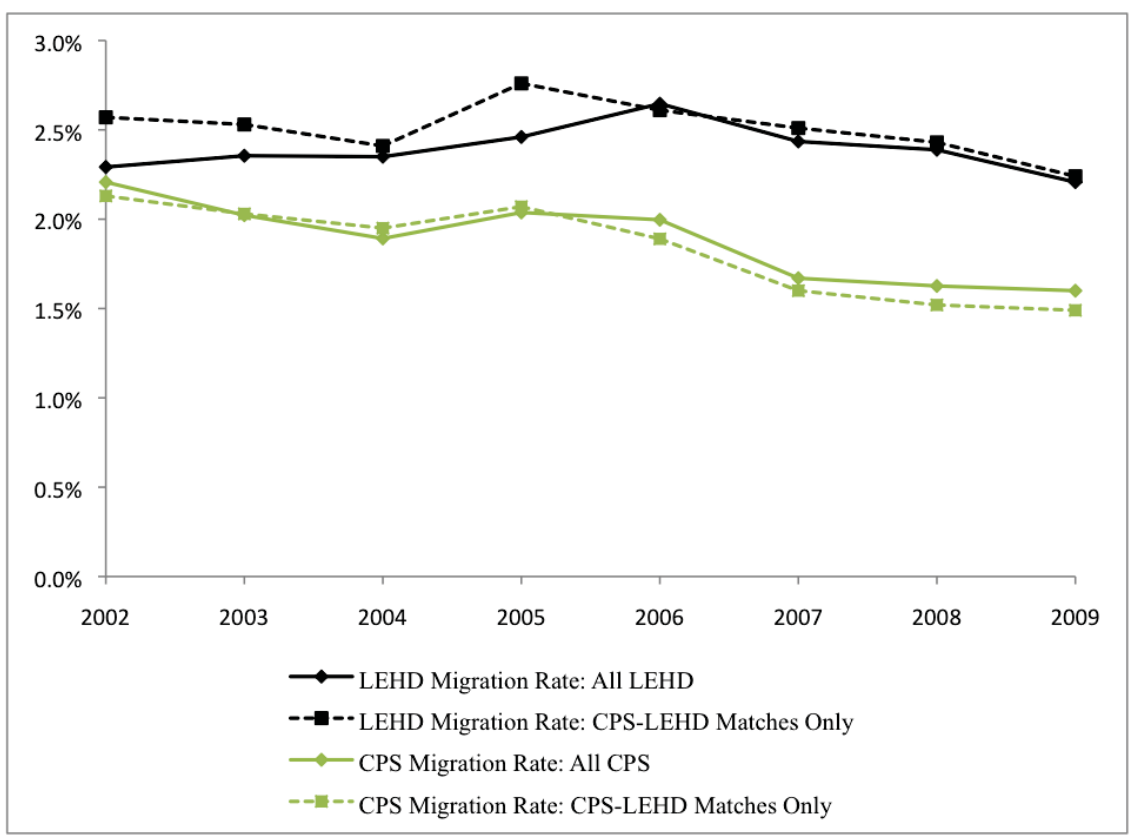

Notes: The "CPS-LEHD Matches" are CPS ASEC respondents for a given year, who match to LEHD and have residential information for that year, the three previous years (i.e., the year pair for which states of residence are compared to determine migration, plus the two previous years), and the two subsequent years. All series are calculated for the population age 16-64 in the reference year. 
Figure 3: Matched CPS-LEHD Migration Rates

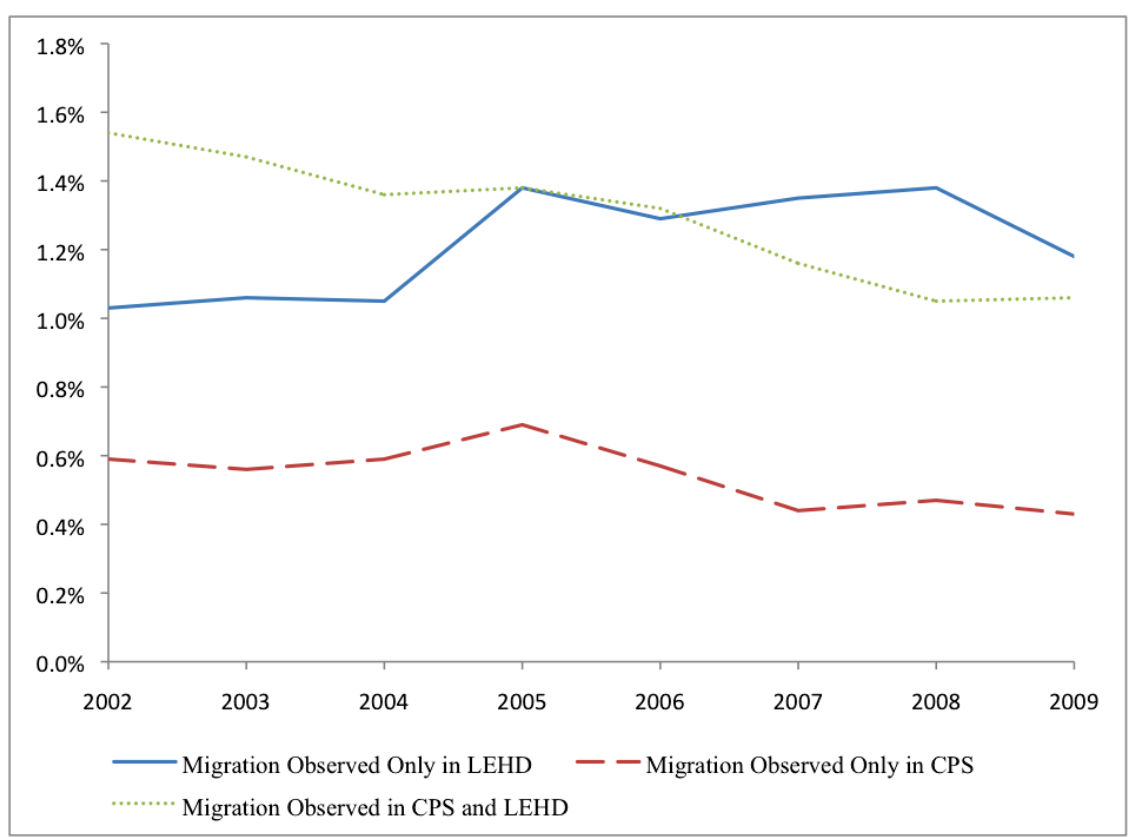

Notes: CPS ASEC respondents for a given year age 16-64 who match to LEHD and have residential information for that year, the three previous years (i.e., the year pair for which states of residence are compared to determine migration, plus the two previous years), and the two subsequent years. 
Figure 4: Employer-to-Employer Transition Rates

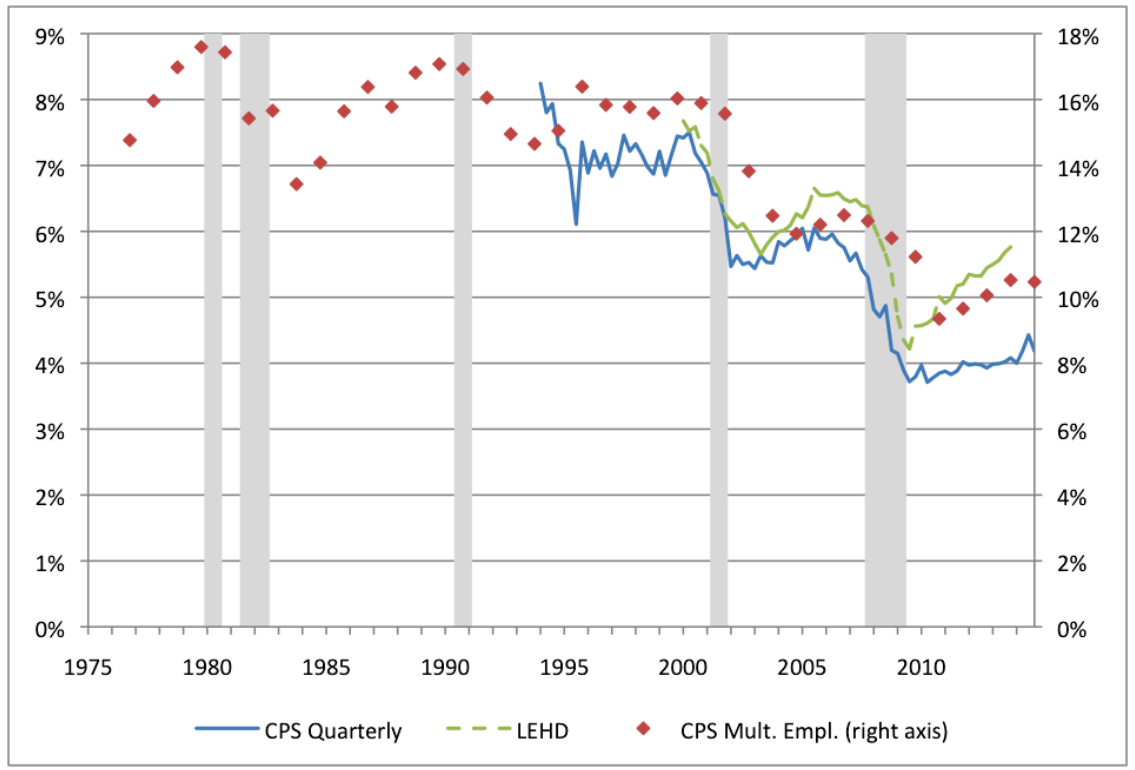

Notes: Shaded areas denote recessions as determined by the National Bureau of Economic Research. Quarterly data are seasonally adjusted. CPS monthly data are converted to quarterly via addition following Hyatt and Spletzer (2013). The second and third quarters of 1995 are missing one month each due to changes made between June and August in the CPS monthly files. The CPS multiple employers series is constructed from the CPS ASEC and coded to the first quarter, and measures the rate of respondents reporting two or more employers in the last year.

Figure 5: Interstate Migration, Residential and Economic

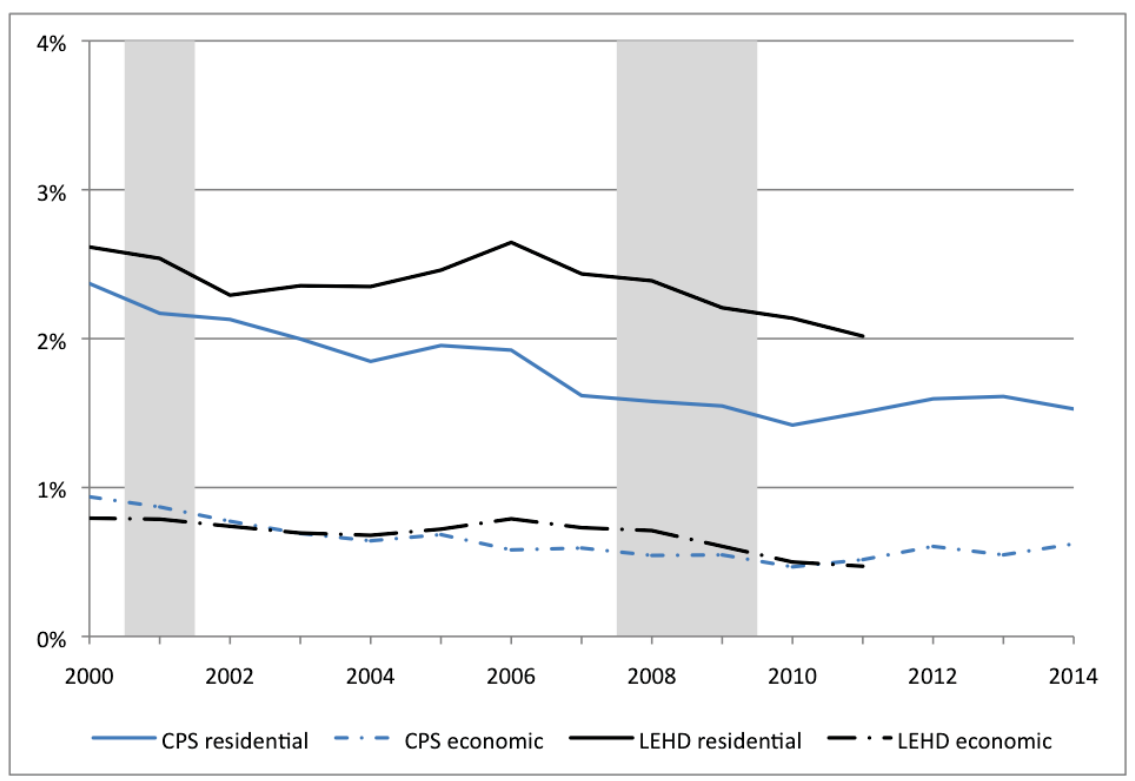

Notes: Shaded areas denote recessions as determined by the National Bureau of Economic Research. 
Figure 6: Change in Log Earnings

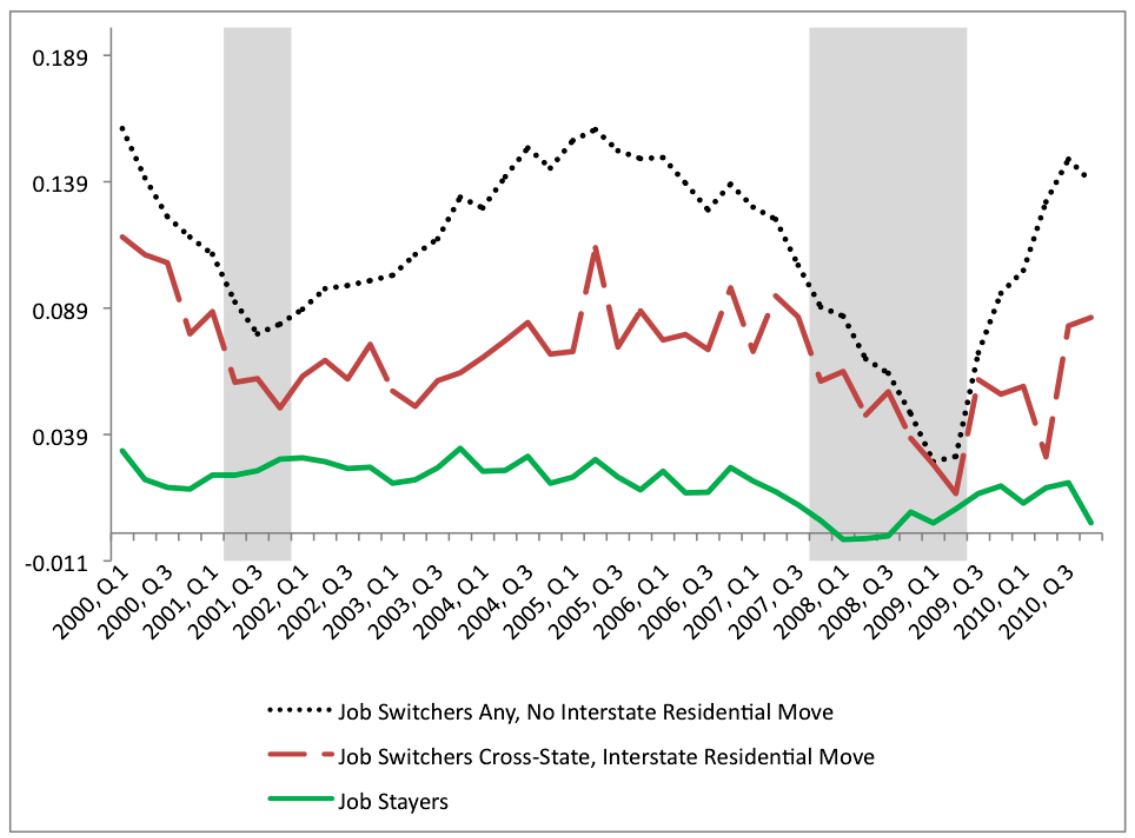

Notes: For each category, a point represents the median difference of: log earnings for one year after the quarter minus log earnings one year prior to the quarter. The sample is initially restricted to workers who have earnings every quarter for 4 quarters prior to a quarter of interest and 4 quarters after. The "Job Stayers" Sample are workers who stayed at the same job during these two years around the quarter. "Job Switchers Any, No Interstate Residential Move" are workers who had any dominant employer-to-employer transition during that quarter, and who did not have an interstate residential move. "Job Switchers CrossState, Interstate Residential Move" are workers who had a dominant employer-to-employer transition across two states during that quarter, and who did had an interstate residential move. Shaded areas denote recessions as determined by the National Bureau of Economic Research. 
Table 1: CPS-LEHD Matches: Migration Observed Only in CPS in Year $t$

\begin{tabular}{ccccc}
\hline Year & $\begin{array}{c}\text { Observed CPS } \\
\text { Move Occurs } \\
\text { One Year Later } \\
\text { in LEHD }\end{array}$ & $\begin{array}{c}\text { Observed CPS } \\
\text { Move Occurs } \\
\text { One Year Before } \\
\text { in LEHD }\end{array}$ & $\begin{array}{c}\text { Border State } \\
\text { move observed } \\
\text { in CPS, no } \\
\text { move in LEHD, } \\
\text { but same origin } \\
\text { state }\end{array}$ & Residual \\
2002 & $23.2 \%$ & $11.0 \%$ & $20.9 \%$ & $45.0 \%$ \\
2003 & $26.4 \%$ & $11.7 \%$ & $19.2 \%$ & $42.7 \%$ \\
2004 & $31.6 \%$ & $11.7 \%$ & $23.0 \%$ & $33.6 \%$ \\
2005 & $27.1 \%$ & $9.4 \%$ & $24.3 \%$ & $39.3 \%$ \\
2007 & $32.1 \%$ & $8.0 \%$ & $22.4 \%$ & $37.5 \%$ \\
2008 & $32.3 \%$ & $11.2 \%$ & $20.2 \%$ & $36.4 \%$ \\
\hline
\end{tabular}

${ }^{a}$ CPS ASEC respondents for a given year age 16-64 who match to LEHD and have residential information for that year, the three previous years (i.e., the year pair for which states of residence are compared to determine migration, plus the two previous years), and the two subsequent years, who also reported moving across states in the CPS but who did not change residence in the LEHD. 
Table 2: Employment Migration and Employer-to-Employer Transitions

\begin{tabular}{lcccc}
\hline & 2000 & 2010 & $\begin{array}{c}\% \text { pt } \\
\text { change }\end{array}$ & $\begin{array}{c}\text { Proportionate } \\
\text { change }\end{array}$ \\
\hline LEHD & & & \\
Emp-to-Emp Transition Rate (Qtr) & $7.3 \%$ & $5.0 \%$ & $-2.3 \%$ & $-37.3 \%$ \\
Interstate Migration Rate & $2.6 \%$ & $2.1 \%$ & $-0.5 \%$ & $-20.1 \%$ \\
Economic Migration Rate & $0.8 \%$ & $0.5 \%$ & $-0.3 \%$ & $-45.5 \%$ \\
CPS & & & & \\
Multiple Employers Rate & $15.4 \%$ & $10.8 \%$ & $-4.7 \%$ & $-35.2 \%$ \\
Emp-to-Emp Transition Rate (Qtr) & $6.9 \%$ & $3.8 \%$ & $-3.2 \%$ & $-59.2 \%$ \\
Interstate Migration Rate & $2.5 \%$ & $1.5 \%$ & $-1.0 \%$ & $-50.2 \%$ \\
CPS Migration Reason & & & & \\
New job/job transfer & & & & \\
Lost job/job search & $0.9 \%$ & $0.5 \%$ & $-0.5 \%$ & $-67.0 \%$ \\
Other job-related & $0.1 \%$ & $0.1 \%$ & $0.0 \%$ & $2.5 \%$ \\
Family & $0.2 \%$ & $0.1 \%$ & $-0.1 \%$ & $-67.2 \%$ \\
Housing & $0.6 \%$ & $0.4 \%$ & $-0.2 \%$ & $-40.0 \%$ \\
Other & $0.3 \%$ & $0.1 \%$ & $-0.1 \%$ & $-53.2 \%$ \\
\hline
\end{tabular}

${ }^{a}$ All series annual unless denoted except for employer-to-employer transition rates, which are quarterly and labeled by (Qtr.). Rates are calculated for individuals ages 16-64, excluding those in the Armed Forces and residing in group quarters, and any observations in the CPS with allocated or imputed migration values. Within the CPS, gross residential rates are weighted with the supplement weight. We calculate annual job change rates in the CPS ASEC using the method outlined in Farber (1999). The LEHD employer-to-employer transition rate includes both within-quarter and adjacent-quarter transition of a workers dominant job (i.e. the job associated with the highest earnings), see Hyatt and McEntarfer (2012) The denominator is the total number of dominant jobs. We report the employer-to-employer transition rate from the first quarter of 2000 and the first quarter of 2010 after seasonal adjustment. Interstate migration is calculated from the LEHD data. The Proportionate change column reports the difference between the rate in 2010 and in 2000, divided it by the average of the rate in 2000 and in 2010. Some percentage point do not equal the difference in columns due to rounding (differences and proportionate change are exact at two decimal points). CPS migration reason categories follow Kaplan and Schulhofer-Wohl (2015). 
Table 3: Decomposition of Residential and Economic Migration Rates

\begin{tabular}{|c|c|c|c|c|}
\hline & \multicolumn{2}{|c|}{ Residential Migration } & \multicolumn{2}{|c|}{ Economic Migration } \\
\hline & $\mathrm{CPS}$ & LEHD & $\mathrm{CPS}$ & LEHD \\
\hline 2000 & $2.4 \%$ & $2.6 \%$ & $0.9 \%$ & $0.8 \%$ \\
\hline 2010 & $1.5 \%$ & $2.1 \%$ & $0.5 \%$ & $0.5 \%$ \\
\hline Change & $-0.9 \%$ & $-0.5 \%$ & $-0.5 \%$ & $-0.3 \%$ \\
\hline \multicolumn{5}{|c|}{$\%$ of change explained by: } \\
\hline \multicolumn{5}{|c|}{ Worker Characteristics } \\
\hline Gender & $0.0 \%$ & $0.4 \%$ & $0.0 \%$ & $0.2 \%$ \\
\hline Age & $7.1 \%$ & $15.5 \%$ & $9.1 \%$ & $12.0 \%$ \\
\hline Race and Ethnicity & $1.3 \%$ & $0.8 \%$ & $1.1 \%$ & $1.2 \%$ \\
\hline Education & $-4.7 \%$ & $-0.1 \%$ & $-7.8 \%$ & $0.4 \%$ \\
\hline Employment, Previous Year & - & $-1.9 \%$ & - & $11.4 \%$ \\
\hline Employment, Subsequent Year & $-4.2 \%$ & $-1.2 \%$ & $1.8 \%$ & $24.6 \%$ \\
\hline \multicolumn{5}{|c|}{ Firm characteristics } \\
\hline Industry, Previous Year & - & $-2.3 \%$ & - & $-1.1 \%$ \\
\hline Industry, Subsequent Year & $-1.1 \%$ & $-1.4 \%$ & $0.1 \%$ & $-0.3 \%$ \\
\hline Firm Size, Previous Year & - & $-0.5 \%$ & - & $-1.2 \%$ \\
\hline Firm Size, Subsequent Year & - & $-0.4 \%$ & - & $-1.0 \%$ \\
\hline Firm Age, Previous Year & - & $3.7 \%$ & - & $0.8 \%$ \\
\hline Firm Age, Subsequent Year & - & $4.7 \%$ & - & $2.1 \%$ \\
\hline
\end{tabular}

\footnotetext{
${ }^{a}$ We group age into the following groups: 16-18, 19-21, 22-24, 25-34, 35-44, 45-54, and 55-64. We group race and ethnicity into Hispanic of any race, White and not Hispanic, Black and not Hispanic, Asian and not Hispanic, and a final category that includes those who are not Hispanic and any other race or more than one race. We group education into less than high school, high school, some college, and college and beyond. Industries are grouped into NAICS supersectors. Industry in the administrative records data refers to the industry associated with the workers dominant job. Similarly, we use the firm size and age of the dominant job prior to migration for the Firm Size and Firm Age categories. We group firm age into the following groups of years: $<1,2-3,4-5,6-10$ and, $>10$. We group firm size into the following numbers of employees: <20, 20-49, 50-249, 250-499, and >499. We classify an interstate residential migration as workers in the LEHD who resided within a different state the subsequent year. The CPS ASEC is used for the CPS migration rates. Both shares and rates are weighted with the CPS supplement weight.
} 


\section{Appendix A: Supplemental Tables and Figures}

Table A1: Correlations Between Migration and Employer-to-Employer Measures

\begin{tabular}{lccc}
\hline \multicolumn{4}{c}{ Correlations: $1981-2014$} \\
& $\begin{array}{c}\text { CPS } \\
\text { Migration }\end{array}$ & $\begin{array}{c}\text { IRS } \\
\text { Migration }\end{array}$ & $\begin{array}{c}\text { CPS } \\
\text { Multiple } \\
\text { Employers }\end{array}$ \\
\cline { 2 - 4 } CPS & & & \\
Migration & 1 & & \\
$\begin{array}{l}\text { IRS } \\
\text { Migration }\end{array}$ & 0.841 & 1 & \\
$\begin{array}{l}\text { CPS } \\
\text { Multiple }\end{array}$ & 0.867 & 0.703 & \\
Employers & & & \\
\hline
\end{tabular}

Correlations: 2000-2014

\begin{tabular}{|c|c|c|c|c|c|c|c|}
\hline & $\begin{array}{c}\text { CPS } \\
\text { Migration }\end{array}$ & $\begin{array}{c}\text { IRS } \\
\text { Migration }\end{array}$ & $\begin{array}{c}\text { CPS } \\
\text { Multiple } \\
\text { Employers }\end{array}$ & $\begin{array}{c}\text { ACS } \\
\text { Migration }\end{array}$ & $\begin{array}{c}\text { LEHD- } \\
\text { CPR } \\
\text { Migration }\end{array}$ & $\begin{array}{l}\text { LEHD } \\
\text { Emp-to- } \\
\text { Emp }\end{array}$ & $\begin{array}{l}\text { CPS Emp- } \\
\text { to-Emp }\end{array}$ \\
\hline $\begin{array}{l}\text { CPS } \\
\text { Migration }\end{array}$ & 1 & & & & & & \\
\hline $\begin{array}{l}\text { IRS } \\
\text { Migration }\end{array}$ & 0.665 & 1 & & & & & \\
\hline $\begin{array}{l}\text { CPS } \\
\text { Multiple } \\
\text { Employers }\end{array}$ & 0.916 & 0.749 & 1 & & & & \\
\hline $\begin{array}{l}\text { ACS } \\
\text { Migration }\end{array}$ & 0.835 & 0.859 & 0.816 & 1 & & & \\
\hline $\begin{array}{l}\text { LEHD } \\
\text { Migration }\end{array}$ & 0.688 & 0.917 & 0.768 & 0.89 & 1 & & \\
\hline $\begin{array}{l}\text { LEHD } \\
\text { Emp-to- } \\
\text { Emp }\end{array}$ & 0.82 & 0.865 & 0.835 & 0.951 & 0.868 & 1 & \\
\hline $\begin{array}{l}\text { CPS Emp- } \\
\text { to-Emp }\end{array}$ & 0.915 & 0.8 & 0.91 & 0.951 & 0.856 & 0.933 & 1 \\
\hline
\end{tabular}

\footnotetext{
${ }^{a}$ Quarterly LEHD and CPS employer-to-employer transition data are annualized by taking an average for each year. Correlations are using the year intervals listed above, with the following exceptions. Migration data are missing from the CPS series for 1985, and are missing from the IRS series for 1982 and 1983, and years 2012 and 2013 are excluded from tabulation because of a significant methodology change that affects those years. The ACS migration and LEHD employer-to-employer transition rate series end in 2013. The LEHD migration series ends in 2011. The LEHD employer-to-employer transition series uses a subset of states that are available in the year 2000, see text for additional details of the construction of each data series. The LEHD and CPS quarterly employer-to-employer transition rates have correlations with the ACS migration rate that distinct at the fifth decimal point and so appear identical due to rounding.
} 
Table A2: CPS-LEHD Matches: Immediately Reversed Migration

\begin{tabular}{ccc}
\hline Year & $\begin{array}{c}\text { LEHD } \\
\text { migration, No } \\
\text { CPS migration }\end{array}$ & $\begin{array}{c}\text { Migration in } \\
\text { CPS and LEHD }\end{array}$ \\
\hline 2002 & $18.2 \%$ & $6.8 \%$ \\
2003 & $15.8 \%$ & $5.9 \%$ \\
2004 & $14.9 \%$ & $7.7 \%$ \\
2005 & $15.5 \%$ & $7.6 \%$ \\
2006 & $12.5 \%$ & $11.3 \%$ \\
2007 & $14.9 \%$ & $7.2 \%$ \\
2008 & $14.2 \%$ & $8.8 \%$ \\
2009 & $17.7 \%$ & $9.2 \%$ \\
\hline
\end{tabular}

${ }^{a}$ CPS ASEC respondents for a given year age 16-64 who match to LEHD and have residential information for that year, the three previous years (i.e., the year pair for which states of residence are compared to determine migration, plus the two previous years), and the two subsequent years, who also changed residence in the LEHD between the reference year and the prior year. Percentages report the rate at which such moves are immediately reversed: i.e., the state of residence in the years previous and subsequent to the reference year are identical. 
Figure A1: Economic Migration Concepts in the CPS

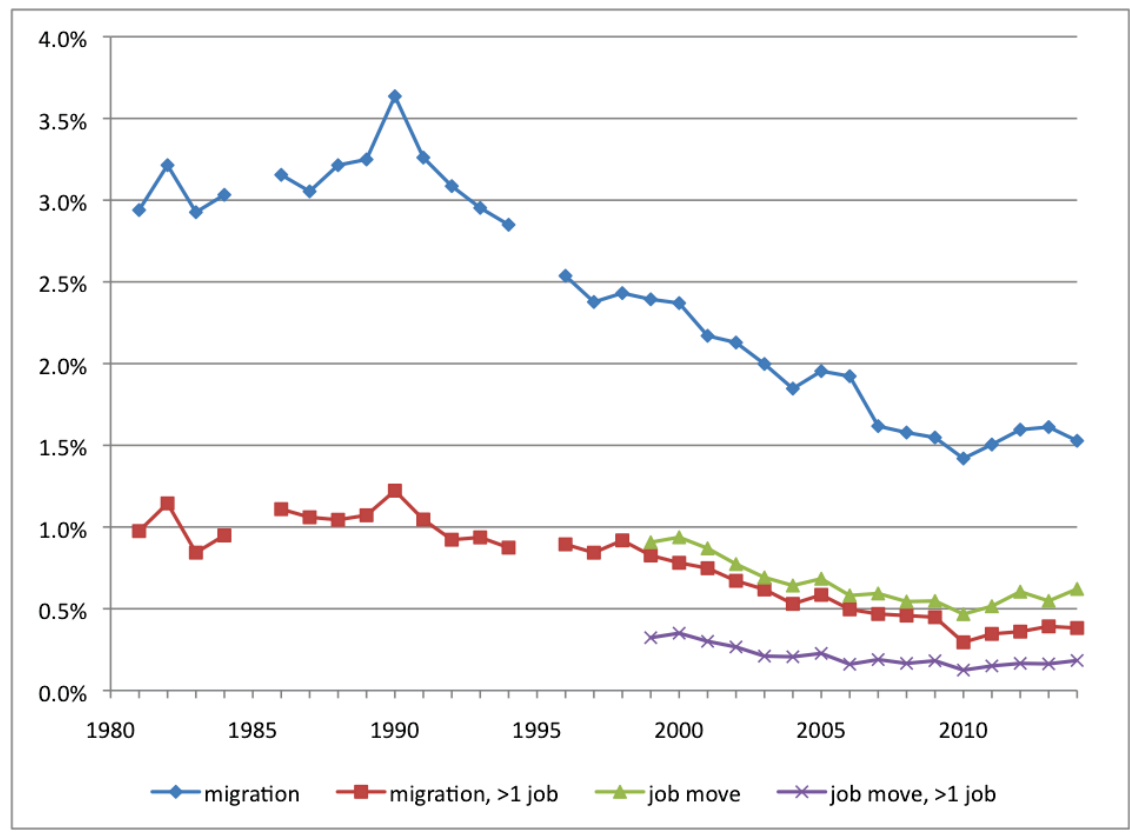

Notes: Residential migration line is taken directly from Figure 1. Also plotted is the percentage of individuals who undertook residential migration and had more than one employer in the previous year. Economic migration line is taken directly from Figure 5. Also plotted is the percentage of individuals who reported economic migration and had more than one employer in the previous year.

Figure A2: Comparison of CPS Interstate Migration Rates Series for Subset of States with Consistent LEHD Data

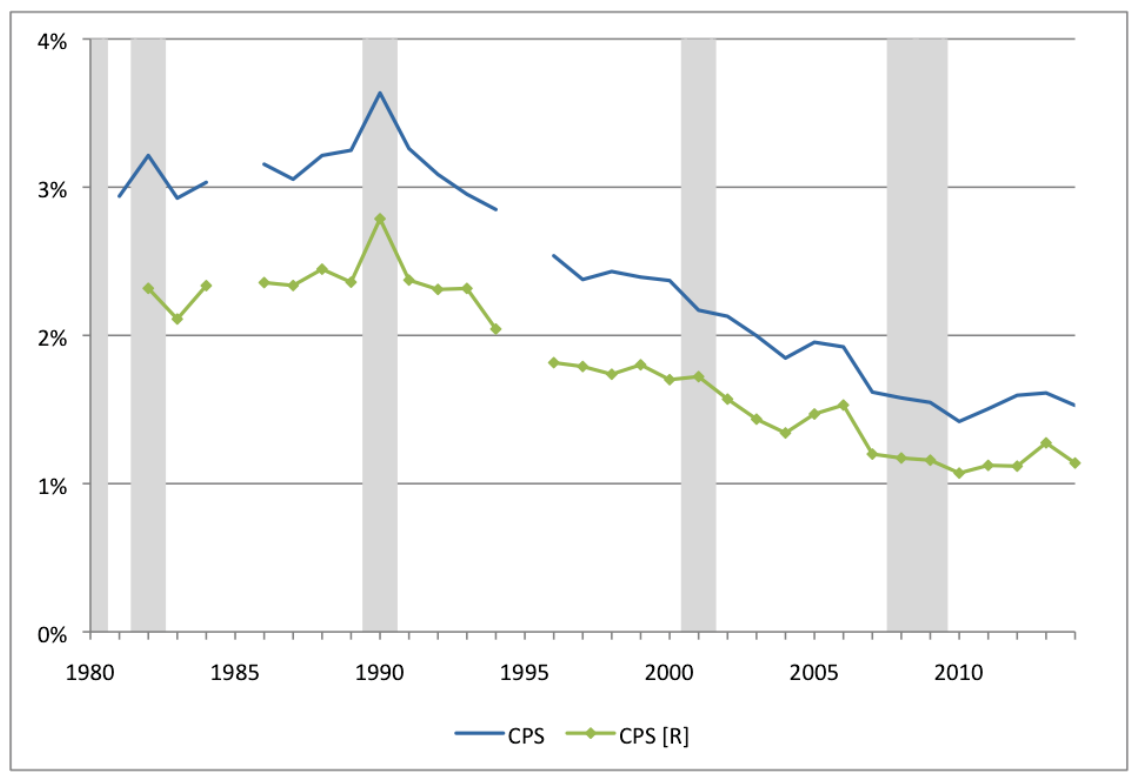

Notes: CPS $[\mathrm{R}]$ contains data for the subset of states that have data in the LEHD going back to the year 2000, for comparison of the CPS time series in Figure 1 to the CPS [R] time series in Figure 3. Note that CPS microdata on the particular state of residence is only available starting in 1982 . 
Figure A3: Economic Migration in CPS and LEHD, CPS only for subset of states

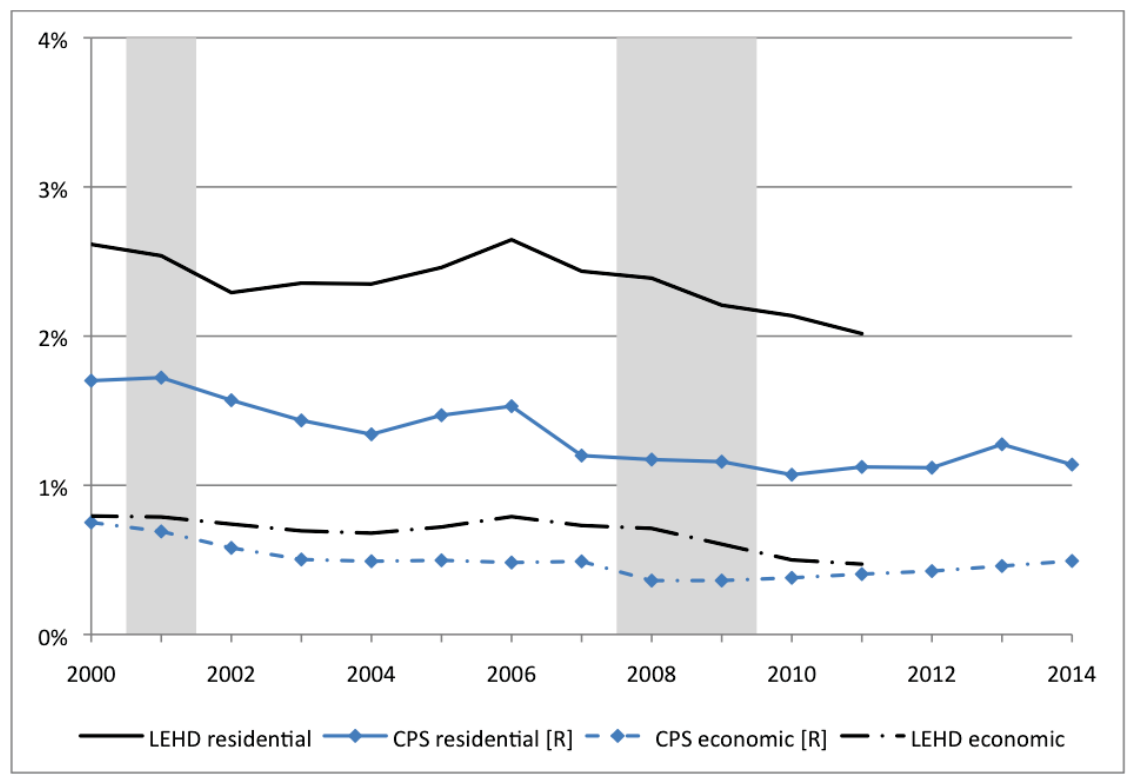

Notes: CPS $[\mathrm{R}]$ contains data for the subset of states that have data in the LEHD going back to the year 2000, for comparison of the CPS time series in Figure 1 to the CPS [R] time series in Figure 3. Note that CPS microdata on the particular state of residence is only available starting in 1982 . 
Appendix B: Selection and the Returns to Migration

The choice to migrate is endogenous and those we observe to have migrated are workers for whom the benefit exceeds the cost. Therefore we measure whether earnings changes for migrants only affect a smaller subset of those most likely to move, given observable characteristics. Specifically, we use a straightforward propensity-score matching method that assumes selection on observables that is, conditional on a vector of observable characteristics, $\mathrm{X}$, the choice of migration is as good as random. We assume that the probability of a cross-state move follows a logit distribution and, using the LEHD data pooled across the years 2000-2010, we estimate:

$$
\operatorname{Pr}(\text { Transition }) \equiv \lambda=\frac{1}{1+\exp \left(X_{i} \beta\right)}
$$

where $\mathrm{X}$ includes worker is age, sex, race earnings, and the age, size, industry, and state of the origin employer.

With these predicted probabilities, we match using the set of migrants and nonmigrants with overlapping support. The top panel of Figure B1 presents the results. There is some evidence that the gap between job switchers who do not undergo an interstate move and those who do widened during the most recent recession when we control for observables, suggesting there was much less to gain in the economic downturn from switching to a job that necessitated a long-distance move. Overall, the measures exhibit levels and trends that are highly similar to those in Figure 6. The bottom panel of Figure B.1 presents matching on the propensity to switch jobs, regardless of location, which produces levels and trends that are even more similar to the original figure. Overall, the returns to migration appear robust to our basic approach to accounting for selection. 
Figure A4: Change in Log Earnings, Propensity Score Matching

(a) Probability of Interstate Residential Move

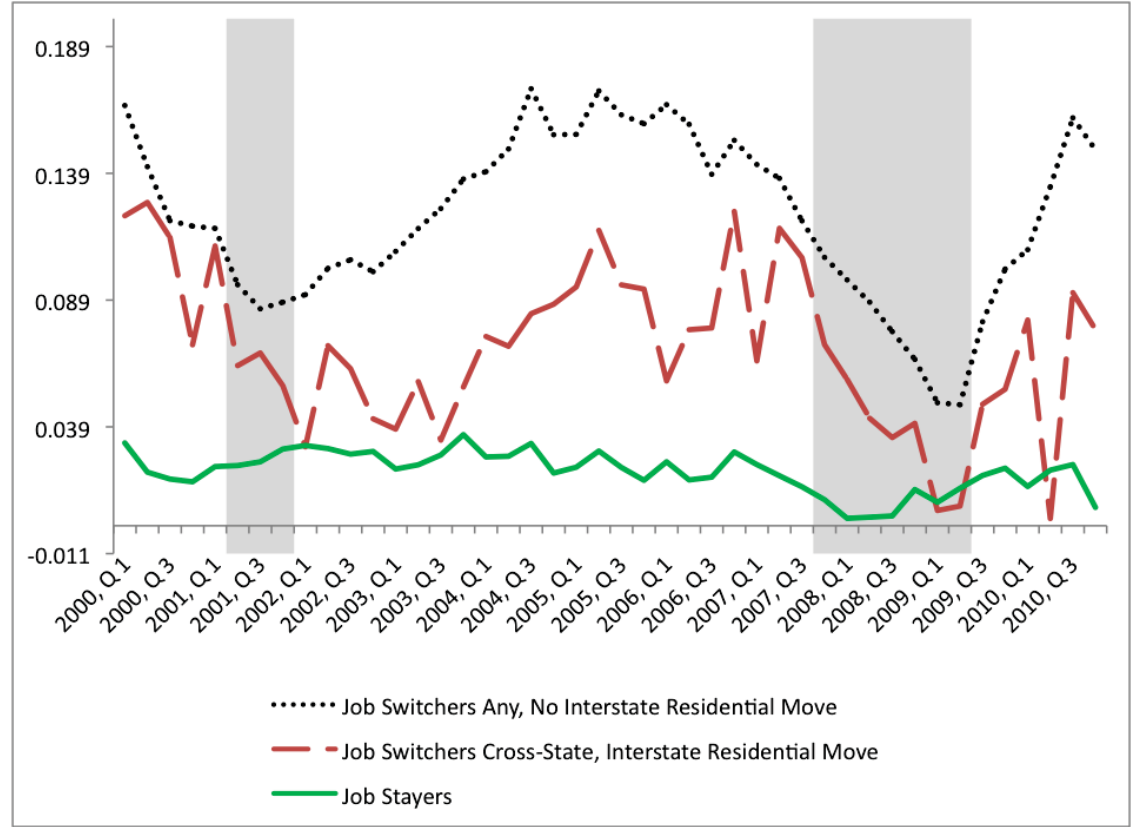

(b) Probability of Job Change

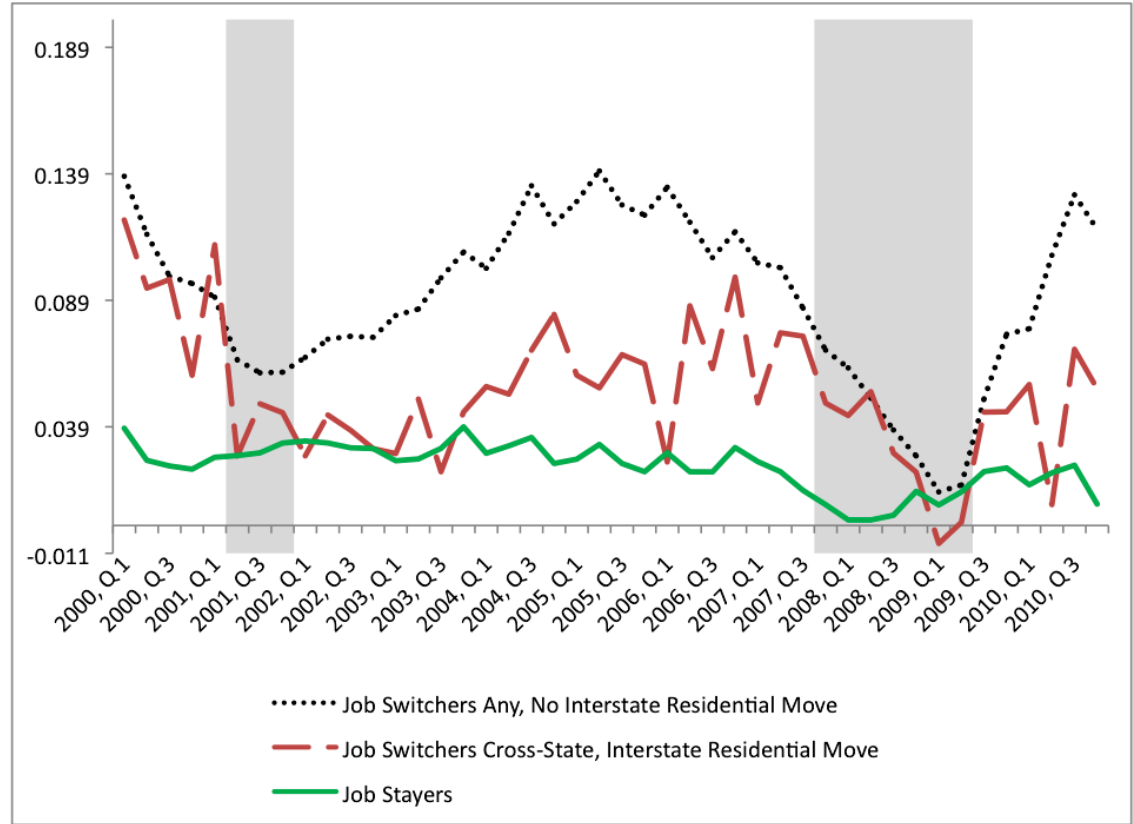

Notes: Panel (a) matches individuals on the probability of undertaking a residential move conditional on observable characteristics. Panel (b) matches individuals on the probability of undertaking any job change conditional on observable characteristics. 